Revista de Filosofía

Volumen 71 (2015) 163-175

\title{
LA IMPORTANCIA DE LA CAUSA INMANENTE EN LA ÉTICA DE SPINOZA
}

\author{
Cristian Andrés Tejeda Gómez \\ Universidad de Chile \\ Máster y Doctorando en Ciudadanía y Derechos Humanos \\ Universitat de Barcelona \\ villolho@hotmail.com
}

Resumen / Abstract

\begin{abstract}
Este artículo pretende señalar la importancia de la causa inmanente al interior de la doctrina de Baruch Spinoza. La Ética es el tratado más importante de Spinoza y reúne el pensamiento maduro del filósofo holandés. La prop. XVIII del libro I tiene un rol fundamental y articula el mundo de la Naturaleza Naturante y la Naturaleza Naturada, mostrando por primera vez la manera en que la causa única se produce y produce todo: de forma inmanente. Intentamos, así, mostrar el rol articulador de la causa immanens en el pensamiento de Spinoza y la importancia de la Ética.
\end{abstract}

Palabras ClaVE: causa inmanente, causa interna, Naturaleza Naturante, Naturaleza Naturada, producción, ética.

THE IMPORTANCE OF IMMANENT CAUSE IN THE SPINOZA'S ETHICS

This article aims to highlight the importance of the immanent cause within the doctrine of Baruch Spinoza. Ethics is the most important treatise written by Spinoza and gathers the mature thought of the Dutch philosopher. Proposition XVIII of book I has a fundamental role and articulates the world of Natura Naturans and Natura Naturata, showing for the first time how the only cause itself occurs and produces all: immanently. We try, as well, show coordinating role of immanens cause of Spinoza's thought and the importance of Ethics.

KEY WORDS: Immanent Cause, Internal Cause, Natura Naturans, Natura Naturata, Production, Ethics.

La importancia de la Ética al interior de la obra de Spinoza

R⿴囗十

La lectura de la Ética impacta en un primer acercamiento. Cinco libros que son objeto de demostración geométrica: definiciones, axiomas, proposiciones y demostraciones. Esta obra, como los grandes textos filosóficos, busca ser expresión de la forma en que se genera todo lo producido en la "realidad". Dios -o la Naturaleza, pues estos términos se identifican- es la causa y la justificación de todo lo producido y Spinoza lo llamará Naturaleza Naturante (Natura Naturans). Las cosas que se producen 
en el mundo el filósofo las llama Naturaleza Naturada (Natura Naturata) y son el efecto de la producción o lo producido.

Sin embargo, no debemos confundirnos: a pesar de apelar a nociones escolásticas, Spinoza les da a ellas un nuevo sentido, pues todo lo que se produce se da "en" una substancia única que produce con la necesidad en que ella misma se da. Por lo mismo, la Naturaleza Naturante y Naturada no corresponden a dos mundos distintos, sino que son la expresión y la diferenciación que se da "en" una única substancia que existe. Con esto, Spinoza anula todo dualismo y desmantela cualquier causa trascendente: tanto lo que produce como lo producido tiene la misma dignidad ontológica y no existe Dios que por voluntad y entendimiento omnipotente puede generar las cosas a su libre arbitrio; también pierde sentido la división creador y creatura o alma y cuerpo, pues todo pasa a formar parte de una misma "filosofía de la naturaleza". No hay ningún elemento que tenga mayor dignidad jerárquica al interior de su filosofía.

La Ética patenta magistralmente esta doctrina y en ella encontramos el pensamiento maduro de Spinoza. Por lo mismo, pensamos que es el instrumento esencial para comenzar cualquier análisis del pensamiento del autor. No queremos restar importancia a otras obras estudiadas extensamente como el Tratado Teológico Político (TTP), el Tratado Político (TP) o el Tratado Breve (VK) o los escritos más cercanos a la filosofía cartesiana como el Tratado de la Reforma del Entendimiento (TI), los Principios de la Filosofía de Descartes (PP) o los Pensamientos Metafísicos $(\mathrm{CM})^{1}$. Más bien, exaltamos esta obra dentro de su producción intelectual, por razones comparativas que señalamos a continuación:

1) El TTP fue redactado durante la escritura de la Ética. Según señala su biógrafo contemporáneo, Steven Nadler, "en el otoño de 1665, Spinoza tuvo que abandonar temporalmente la Ética en tres partes para preparar su Tratado Teológico-Político, es muy probable que tuviera ya lo que entonces consideraba un borrador sustancialmente completo, si bien un borrador que, aunque ampliamente representativo de la versión final, sería significativamente reelaborado en los años subsiguientes" (2004: 309). Al parecer, los pensamientos desarrollados en el intertanto, acompañados por la situación política agitada, tuvieron tal impacto que la Ética proyectada en tres partes que pasó luego a formar un escrito con cinco libros. La Ética se vuelve un pensamiento aún más maduro durante este periodo y no contradice en nada el contenido del TTP; más bien lo envuelve. La Ética introduce una serie de postulados políticos que se encuentran en sintonía con el TTP (por ejemplo, las relaciones entre política, religión y superstición); pero las propuestas ontológicas de la Ética no las encontramos en TTP.

2) El TP es la última obra de Spinoza, sigue una línea de continuidad con el TTP, pero se advierte una radicalización del realismo político. En este sentido, las primeras páginas

1 Estas son las abreviaturas habituales con que se suele mencionar la obra de Spinoza y comenzamos a utilizarlas desde ahora al nombrarlas. Solo falta mencionar la correspondencia que se abrevia (EP). 
advierten que los filósofos suelen tomar los afectos de los hombres como vicios; pero -y este pensamiento va en plena concordancia con la ideas de la Ética-concebir al hombre como desprovisto de pasiones indica una teoría política quimérica. Spinoza rechaza todo esquema utópico y esperanza en pos de una sociedad armoniosa, pues "toda ciencia política que pretenda ser útil debe partir, por el contrario, de una valoración realista de la naturaleza humana y sus pasiones considerada como un necesario fenómeno natural" (Nadler 2004: 460). En este sentido, podríamos decir que la Ética envuelve también temáticamente el TP y tiene continuidades y diferencias con el TTP. Étienne Balibar nos señala algunas: "La temática política se independiza de la cuestión teológica, lo cual modifica el punto de partida de la argumentación: no será ya el análisis de un pueblo histórico y la Escritura que transmite el relato producido por él, sino el tejido pasional de las sociedades humanas que, según se afirma en la célebre apertura del TP, los "filósofos" raramente han sido capaces de comprender" (1996: 12).

3) ElTI es un texto inconcluso dentro de su producción intelectual. Es de común acuerdo plantearlo como uno de los primeros textos originales dentro de la filosofía de Spinoza. Se ha especulado mucho acerca de por qué abandona la escritura de esta obra. Entre otras razones se esgrime la certeza de Spinoza sobre la insuficiencia de esa doctrina. "Decidió a finales de 1659 o principios de 1660 abandonar el Tratado y volver a empezar; esta vez sobre lo que habría de convertirse en el Breve Tratado de Dios, del Hombre y su Felicidad, cuyo capítulo metodológico se solapa con el material del Tratado en varios aspectos" (Nadler 2004: 244). Con relación a la Ética, existe una notoria diferencia en la manera de expresar su doctrina epistemológica. En el TI, Spinoza distingue 4 tipos de conocimiento: I. Percepción de oídas o mediante signo arbitrario. II. Percepción por experiencia vaga. III. Percepción inadecuada de la esencia de una cosa a partir de otra. IV. Percepción de una cosa por su esencia o causa próxima (2006: 84-85). En la Ética el número de géneros de conocimiento disminuye a tres (conocimiento inadecuado y dos tipos de conocimiento adecuado: de las relaciones y de la esencia) y se complementan con la doctrina ontológica de la composición de los cuerpos. Solo en la Ética, la doctrina de Spinoza se engrana de tal manera que cobra sentido la unidad de su pensamiento.

4) PP y CM. Estas obras tienen impronta cartesiana y fueron publicadas conjuntamente. Junto con el TTP, fueron los únicos libros que vieron luz pública durante la vida de Spinoza y CM fue inserto como un apéndice de los PP. Spinoza no parece haber tenido un interés directo en estas obras, pues el mismo declara en una carta a Enrique Oldenburg: "cuando en el mes de abril trasladé aquí mi domicilio, me traslade a Amsterdam. Allí, algunos amigos solicitaron de mí que les hiciera una copia de un Tratado que comprendía la segunda Parte de los Principios de Descartes demostrada a la manera de los Geómetras $\mathrm{y}$ un resumen de los puntos fundamentales de la Metafísica, que antaño yo enseñara a cierto joven ante el cual no quería exponer abiertamente mis opiniones. Después me rogaron que compusiera según el mismo método también la primera parte, y ello con la máxima celeridad. Para no defraudar a estos amigos me puse al instante a hacer dicho trabajo, que pude acabar en dos semanas" (Spinoza 1998: XIII, 51). 
5) La suerte del VK es singular. Fue encontrado en el año 1703 por dos estudiosos alemanes y se creyó en una primera instancia que era un Ética pequeña, escrita sin el modo geométrico y con la redacción de un capítulo inédito sobre "el diablo". Fue escrito originalmente en latín, pero solo llegó a nosotros su traducción holandesa. Se dudó incluso de la autenticidad del VK, pero es acuerdo común aceptarla como una obra de Spinoza debido a los claros paralelos que existen entre él y la Ética (Spinoza, 1990: 8-11). El VK reúne muchos de los elementos de la obra madura de Spinoza y se destaca su apéndice. En él se encuentra un esbozo de las ideas de la Ética redactadas al modo geométrico, lo que daría cuenta de que mientras redactaba y corregía este libro, Spinoza ya pensaba en la Ética y sentía cierta insatisfacción por los resultados obtenidos en el VK.

6) La Ética. Por lo anteriormente señalado, la redacción de la Ética debió ser una tarea ardua. Comienza a ser concebida a principios de 1660 y terminada en años posteriores a 1665 según parecen dar cuenta sus relaciones epistolares. Como deja claro Nadler, las temáticas del VK en su mayoría están contenidas en la Ética y cierta insatisfacción con sus pensamientos lo tenían ya en 1661 trabajando en ella (Nadler 2004: 277). En ese sentido, como aclaración y perfeccionamiento de nociones del VK, creemos que se justifica la mayor preponderancia que damos a la Ética en nuestra interpretación.

Con relación a las primeras obras de matriz cartesiana, los PP y CM, la Ética nos muestra una doctrina original y no solo deja entrever tímidamente el pensamiento de Spinoza. El TI es un escrito inacabado, y como hemos evidenciado, contiene ciertos momentos de la epistemología de Spinoza que son pulidos en la Ética. Los dos textos propiamente políticos, el TTP y el TP, son realizados por Spinoza durante y luego de haber escrito la Ética. No encontramos, como en las obras anteriores, contradicciones o desavenencias mayores. Más bien, por las materias tratadas, se aprecia una preocupación y un ahondamiento de temas ya contenidos en la Ética como doctrina general.

\section{La inmanencia en la obra de Spinoza y su relevancia al interior de la Ética}

Solamente dos veces es mencionada en la Ética la palabra inmanencia y siempre calificando la causa (Giancotti 1970: 135). Así señala el detallado estudio de Emilia Giancotti, el Lexicon Spinozanium, que reúne exhaustivamente el sentido y lugar de aparición de los conceptos de Spinoza en la totalidad de su obra y en su idioma original. Sin embargo, si seguimos lo que Spinoza señala en el VK podemos decir que la causa inmanente es lo mismo que la causa interna: "Todo efecto de una causa inmanente o interna (que para mí es una misma) no es posible que pueda perecer ni cambiar mientras permanezca esa causa suya" (Spinoza 1990: 165). Teniendo en cuenta este símil, encontramos la causa interna mencionada una vez en la Ética: "Llamo Contento de sí mismo a la alegría acompañada de la idea de una causa interior" (Spinoza 2011: III, prop. XXX, schol., 246). Sin embargo, causa interna aquí no parece encontrarse en un lugar de tanta importancia como en el que aparece la causa inmanente. En otras obras latinas de Spinoza no volvemos a encontrar la causa inmanente. Sin embargo, en PP 
aparece causa interna dos veces con la intención de distinguirla de la causa externa; cuatro veces en CM: dos en I, cap. III para asimilarla a la fuerza de la esencia de las cosas y dos veces más en II, cap. IV para responder cuáles son las causas del cambio; finalmente, en el TP se menciona una vez para hablar sobre las causas que pueden disolver a los Estados aristocráticos (Giancotti 1970: 135).

Encontramos también en el Lexicon Spinozanium un apéndice con el estudio de los escritos de Spinoza en idioma neerlandés. Dos cartas del EP: la XXXVIII y la XLIV; dos escritos atribuidos a Spinoza: Reeckening van de Regenbogen (Cálculo algebraico del Arco Iris) y Reeckening van de Kanssen (Cálculo de probabilidades); y el importante VK, escrito en latín, pero del que solo se encontró su manuscrito neerlandés. Aquí encontramos once veces mencionada la palabra inmanencia (inblyvende) siempre calificando la causa y seis veces nos topamos con la causa interna (innerlyke oorzaak) ${ }^{2}$ (Giancotti 1970: 1265-1266).

El VK es un texto importante dentro de la producción filosófica de Spinoza. Si asumimos lo que dice su biógrafo contemporáneo Steven Nadler, Spinoza "debía sentir una cierta insatisfacción ante su Breve Tratado, y fue más o menos en esta época cuando le escribió a Oldenburg diciéndole que la presentación rigurosamente geométrica de sus doctrinas sobre Dios y la sustancia estaban empezando a consumir gran parte de sus energías intelectuales. Dicho en pocas palabras, hacia finales de 1661, Spinoza ya estaba trabajando en lo que habían de ser las partes iniciales de su Ética" (Nadler 2004: 277). El VK presenta muchas de las temáticas contenidas en la Ética, pero no expuestas al modo geométrico.

Sin embargo, en el VK ocurre algo inquietante: insiste Spinoza en mencionar la causa inmanente, pero va posponiendo su resolución conceptual para más adelante: "Por otra parte, ya hemos establecido, como haremos de nuevo más adelante, que fuera de Dios no existe absolutamente nada y que él es una causa inmanente" (Spinoza 1990: I, cap. II, 69). Al parecer, siente la necesidad de insistir en el sentido de lo que entiende por causa inmanente, como si olvidase algo cada vez. De hecho, en la conclusión del primer diálogo, la Razón le responde a la Concupiscencia-los otros dialogantes son el Amor y el Entendimiento-: "tú dices esto, porque tan solo tienes noticias de la causa transitiva y no de la causa inmanente, la cual no produce en absoluto algo fuera de ella" (Spinoza 1990: Z II, 75) y con eso añade elementos: la oposición a lo transitivo y la producción interior de la causa. En el segundo diálogo entre Erasmo y Teófilo sigue aun más puliendo el término y solo reaparece hacia el final del cap. XXX del libro II,

2 La traducción de immanens en la Ética hecha por Nico van Suchtelen al neerlandés es inwonende. En VK, se utiliza la palabra inblydende para designar la inmanencia. Admitimos desconocer la causa de esta diferencia. Quizá la decisión radique en los más de dos siglos de diferencias lingüísticas que median entre la escritura del VK y la traducción de la Ética propuesta por el profesor. Para términos de este artículo asumimos que inwonende e inblydende traducen el sentido de inmanencia; sin embargo, no modifica mayormente el contenido de este artículo. 
"sobre la libertad", donde se habla sobre la perfección de unir todo lo producido a una misma única naturaleza.

En cambio, en la Ética, causa inmanente aparece mencionada solo dos veces en la prop. XVIII: una en la misma proposición y otra en su demostración. Entonces, ¿por qué debemos en el estudio de Spinoza darle tanta preeminencia a la Ética y a la causa inmanente? Una primera respuesta breve sería: no decimos que el concepto de inmanencia tenga una preeminencia jerárquica sobre otros de igual importancia, solo decimos que es un punto de partida importante que sirve para articular y entender toda la doctrina de Spinoza. Desde esa óptica, se deducen y se articulan fácilmente una gran cantidad de conceptos esenciales que ya hemos mencionado como sustancia, Dios o naturaleza.

La segunda respuesta es extensa y alude al pensamiento mismo de Spinoza. Si asumimos la premisa establecida anteriormente por Nadler, que la Ética comienza a ser redactada por disconformidad con el VK, diremos: primero, algo debe estar mejor articulado en la Ética para que Spinoza solo necesitara mencionar dos veces el concepto de causa inmanente; y segundo, ese pulimiento de las nociones debe representar para términos de nuestra hipótesis una elevación del término inmanencia a un concepto clave en Spinoza. Es lo que pasamos ahora a analizar.

Al hablar de la Ética, Deleuze realiza un análisis sobre las velocidades y el ritmo del pensamiento. Se irá más despacio o lento, se irá a un tipo de ritmo, según las necesidades de ese pensamiento y, en tal sentido, Deleuze manifiesta que "Spinoza no comienza por la sustancia absoluta, no comienza por Dios". Dios es alcanzado hasta la def. VI, porque parte con "el estatuto de los elementos constituyentes de la sustancia". La necesidad de la exposición y su adecuada velocidad lo conminan a esperar el momento adecuado. Incluso solo hasta la proposición X y XI se alcanza a Dios al nivel de las demostraciones (Deleuze 2008: 36-37).

Creemos que ese mismo juego de ritmos y velocidades es el que forja la prop. XVIII de la Ética, momento en que se establece: "Dios es causa inmanente, pero no transitiva de todas las cosas" (Spinoza 2011: I, prop. XVIII: 85), y le dará así Spinoza a la causa inmanente una posición singular dentro del primer libro y al interior de toda su doctrina. Spinoza va lento y en ciertos momentos frena y acelera inmediatamente. Como decíamos, la definición de Dios se da en def. VI, luego se siguen siete axiomas y las proposiciones de este libro, que son 36, parten con la substancia. Pero todos los caracteres que Spinoza da a la substancia hasta la prop. VI o son negativos o intentan diferenciar a esa substancia: no pueden darse dos substancias, no puede ser producida una substancia por otra, la substancia es anterior a sus afecciones... La prop. VII da un salto cualitativo y positivo, pues afirma plenamente: "A la naturaleza de una substancia pertenece el existir” (2011: prop. I, VII, 61). Luego, en la prop. XI, aparece por primera vez Dios y sus atributos, afirmados como "existentes" y tenemos un segundo momento plenamente afirmativo. Pero a partir de allí hay un nuevo lento movimiento desde la prop. XII hasta la XVII -marcada por una constante alusión del verbo "concebir" (concipire). Spinoza nos muestra reiteradamente cómo "concebir" a este Dios y cómo debemos asumir sus características propias, siempre observando el camino recorrido. La 
prop. XVI no utiliza el "concebir", pero sí remarca el "deben seguirse" (sequi debent), dándonos pistas de hacia dónde debemos mirar; la prop. XVII no contiene ninguna de esas conjugaciones verbales, pero su demostración aún tiene un carácter negativo: Dios actúa bajo sus propias leyes, pero carece de voluntad y entendimiento. ¿Cómo podría haber causa inmanente, si Dios pudiera con su voluntad y su entendimiento hacer diferente lo que ahora es? En tal caso, Dios sería causa trascendente o transitiva, pues habría distinción jerárquica entre el Creador y lo creado.

Con la prop. XVIII, "Dios es causa inmanente, pero no transitiva de todas las cosas", tenemos una afirmación seca y potente. Spinoza en ninguna de las proposiciones anteriores de este libro menciona la palabra causa. En prop. III la menciona, pero se refiere a la causa sin adjetivos y ahí se señala solamente que una cosa no puede ser causa de otra sin tener algo en común. En cambio, solo la en prop. XVIII encontramos por primera vez la causa calificada al nivel de las proposiciones y la calificación es de inmanente: Dios es causa inmanente de las cosas.

Primeramente, este gesto hace que la idea de inmanencia adquiera una potencia propia, a pesar de no ser casi mencionada en la Ética de Spinoza. A diferencia de VK, aquí la noción de causa inmanente no es desplazada hacia adelante para su posterior pulimiento. Aparece cuando aún el pensamiento de Spinoza va colocando las piezas de aquello que desea exponer con precisión, sobre la base de las definiciones, axiomas y demostraciones hechas. Sabemos de la existencia de la substancia (prop. VII), sabemos de la existencia de Dios (prop. XI), sabemos que se identifican, pero aún no sabemos cómo producen y qué producen como causa.

Eso es lo que nos muestra la prop. XVIII, "Dios es causa inmanente, pero no transitiva de todas las cosas": Dios produce de manera inmanente las cosas que son. Por primera vez al nivel de las proposiciones se mencionan las cosas en el sentido de lo producido y no en el sentido de lo que produce: omnium rerum ${ }^{3}$. En ese sentido, nos encontramos en esta proposición con un punto de intersección clave que une la naturaleza de la sustancia única que se identifica con Dios y las cosas que son "en” Dios: la producción inmanente de todo. A nivel de la demostración, Spinoza no deja dudas y por eso la analizaremos cuidadosamente: a) "Todo lo que es"(Omnia quae sunt): utiliza la palabra "todo" para referirse a las cosas como efectos o modos; b) "es en Dios y debe concebirse por Dios" (in Deo sunt \& per Deum concipi debent): deben ser concebidas "en" Dios, ya que la causa única produce al interior suyo todo lo que es y, además, solo puede ser "concebido" aquello que es "en" por medio de esa causa; de ello se desprende que c) "y así, Dios es causa de todas las cosas que son en él" (adeóque Deus rerum, quae in ipso sunt, est causa), lo que creemos es fácil intuir; pero, d) "además, excepto

3 En la prop. V se menciona "In rerum natura non possunt dari duae, aut plures substantiae ejusdem naturae, sive attributi” (Spinoza 1972: I, prop. V, p. 48), pero creemos que aquí el sentido del texto hace referencia a las características de la natura naturans y, por eso mismo, Vidal Peña ha traducido "en el orden natural no pueden darse..." (Spinoza 2011, I, prop. V, p. 60). 
Dios no puede darse substancia alguna, esto es, cosa alguna, excepto Dios, que sea en sí" (extra Deum nulla potest dari substantiae, hoc est, res, quae extra Deum in se sit). Aquí debemos valorar dos elementos. El primero, el uso de "cosa" (res) solitario deja en claro que nos referimos a las cosas producidas. Segundo, el uso hecho de la partícula "extra": creemos que la traducción de Vidal Peña ${ }^{4}$ al castellano no se ajusta al sentido de la proposición. Traducir, "excepto Dios", nos aleja del significado de la segunda parte de esta proposición, "pero no transitiva" (non verò transiens). Transiens refiere a la trascendencia, es decir, "lo que está afuera", lo "extra" y Dios como causa productora no está afuera sino que está "en", es inmanente. Distinta es la traducción de Atilano Domínguez, quien traduce "fuera de Dios" y así hace justicia a ese sentido5. Pero otras traducciones nos dan la razón: Charles Appuhn traduce al francés "en dehors de Dieu" y R. H. M. Elwes "that is nothing in itself external to God" (Spinoza 2010: Ethica DB). e) Solo así podemos llegar tranquilamente a la conclusión de la demostración: "Luego, Dios es causa inmanente pero no transitiva, de todas las cosas" (Deus ergo est omnium rerum causa immanens, non verò transiens) (Spinoza 2011: I, prop. XVIII, dem., 64).

En el VK, Dios aparece rápidamente, desde el primer momento; pero la Ética parte por la definición de causa sui (causa de sí: aquello cuya esencia implica la existencia). Si VK igualaba explícitamente la causa inmanente y la causa interna, sabemos ahora que Dios como causa de todas las cosas debe ser igualmente causa de sí mismo. Así, se igualan estas tres causas. Pero la manera en que esa causa se produce a sí misma y todas las cosas es inmanente y he ahí la importancia fundamental de la prop. XVIII en la doctrina de Spinoza. Estas son sin dudas aclaraciones y mejoras que hace a la doctrina de VK a partir de una exposición plenamente geométrica. En ese mismo sentido, creemos que Spinoza tenía la seria intención de ubicar la causa inmanente en aquel lugar y esa es una de las innovaciones fundamentales. En ese preciso punto de la Ética, aseveramos, logra Spinoza ya precisar en general todos los elementos de su ontología y solo hace falta desplegarlos.

Este hecho se aprecia al ver cómo avanza la escritura de Spinoza a partir de la prop. XVIII. Antes de ella tenemos tres extensas proposiciones (XV-XVI-XVII) que prepara con cuidado y abundancia: largos párrafos, explicaciones y corolarios (estos aparecen por primera vez en la Ética). Pero expresada la prop. XVIII y hasta la prop.

$4 \quad$ "Todo lo que es, es en Dios y debe concebirse por Dios (por la Proposición 15); y así (por el Corolario 1 de la Proposición 16 de esta parte), Dios es causa de las cosas que son en El: que es lo primero. Además, EXCEPTO Dios no puede darse substancia alguna (por la Proposición 14), esto es (por la Definición 3), cosa alguna EXCEPTO Dios, que sea en sí: que era lo segundo. Luego Dios es causa inmanente, pero no transitiva, de todas las cosas. Q.E.D” (Spinoza, 2011:I, prop. XVIII, dem., p. 85).

$5 \quad$ Traducción de Atilano Domínguez: "Todas las cosas que son, son en Dios y deben ser concebidas por Dios (por 11/15): que es lo primero. Además, FUERA de Dios no puede darse ninguna sustancia (por 1/14), esto es (por 11/d3), una cosa que sea en sí FUERA de Dios: que es lo segundo. Luego Dios es causa inmanente, pero no transitiva, de todas las cosas" (Spinoza, 2000:I, prop. XVIII, dem., p. 55). 
XXXIII -donde hace una pausa explicativa larga- nos encontramos con un texto que avanza rápido, se señalan características velozmente, hay soltura en la pluma. Spinoza, con la afirmación de la causa inmanente, llega a un momento clave y positivo de su doctrina. Por eso, la "causa" aparece calificada por primera vez al interior de las proposiciones; y por eso mismo ubicar la idea de inmanencia en ese momento no puede ser azaroso: inmanencia es la característica de lo que genera y es generado en el mundo existente.

Insistimos, la prop. XVIII tiene un carácter especial, ya que es un momento clave en que toda la filosofía de Spinoza se resume en términos generales y a partir de ella se puede más fácilmente determinar lo que prosigue. Si Dios es causa inmanente, deben existir las cosas producidas por aquella causa. Pero al agregar a la causa el calificativo de inmanente, Spinoza nos aporta de manera clara la forma en que se produce esa causa que es Dios y también la cualidad inmanente que tendrá lo producido. Tal idea la encontramos íntegramente en el VK, pero no tan estrictamente articulada como en la Ética: "la causa más libre y la que mejor conviene a Dios, es la inmanente. Puesto que el efecto de esta causa depende de tal modo de ella que sin ella no puede existir ni ser entendido, tampoco está sometido a ningún otra causa y, por consiguiente, también está tan unido con ella que forman juntos un todo" (1990, II, cap. XXVI: 165). Por lo mismo, la marca inmanente de lo producido será sensu scricto, pues no hay que olvidar el momento negativo de la prop. XVIII: "pero no transitiva de todas las cosas". Con esto, Spinoza expurga a la inmanencia de toda posible asociación con una causa trascendente, ningún intelecto ni voluntad omnipotente puede fundar, dar sentido o generar las cosas del mundo. La Naturaleza Naturante y la Naturaleza Naturada son partes de una misma sustancia que se diferencia o se individua desde su interior.

No solo quisiéramos quedarnos con esta interpretación. Uno de los mayores estudiosos de la Ética, Martial Gueroult señala: l'immanence du Dieu cause est pour Spinoza une thèse fundamentale (Gueroult 1968: 296). Ella "marque une nouvelle étape dans la determination des propes de l'opération divine. Elle achève de fonder la doctrine de l'immanence"7 (1968: 295). Concordamos con esta interpretación por darle una dignidad inequívoca a la idea de inmanencia al resaltarla tan notoriamente.

Gueroult entiende que una de las claves para entender y darle una interpretación adecuada a la Ética es la causa inmanente. Es una idea central que está en el corazón de la obra y Gueroult logra vislumbrar toda su potencia para aunar lo esencial de la doctrina Spinozista en este comentario: “Ainsi qu'on l'a dit, Dieu, de par de la causalité, est immanent aux choses qu'il produit (Prop. 18), tandis que, de par son essence, les choses, devant être toutes en lui, lui sont immanents (Prop. 15). Mais, du fait que la causalité immanente consiste en ce qu'elle produit ses effets à l'intérieur d'elle, l'immanence de Dieu aux choses, impliquée per la causalité immanente, enveloppe

6 "La inmanencia de Dios es para Spinoza una tesis fundamental" (La traducción es nuestra).

7 "Marca una nueva etapa en la determinación de las propiedades de la operación divina. Ella completa el fundamento de la doctrina de la inmanencia" (La traducción es nuestra). 
ipso facto l'immanence des choses à lui-même"8 (1970: 299). Dios envuelve por su causalidad inmanente a las cosas y lo producido es parte de Él.

\section{La definición de inmanencia spinozista y sus características}

Spinoza propone un concepto radical de la inmanencia y recusa todo residuo trascendente para explicar cómo se generan las cosas en el mundo. Entendemos ahora mejor la prop. XVIII de la Ética, "Dios es causa inmanente, pero no transitiva de todas las cosas": en el orden ontológico, la creatura y el Creador tienen la misma dignidad ontológica y cualquier analogía entre ellos solo desemboca en una forma equívoca de nombrar algo que tiene un carácter unívoco. Ni carácter trascendente a ultranza ni búsqueda de conciliaciones: el mundo no necesita dividirse en dos, es solo uno y desde ahí se explica.

$\mathrm{Al}$ interior de esa unidad, la naturaleza se diferencia, porque no hay nada que supere desde el exterior esa cualidad de lo producido. Fraccionar el mundo en dos nos pone en la disyuntiva de encontrar la forma de comunicarlos y la analogía se muestra como un buen aliado en tal búsqueda. Sin embargo, corremos el riesgo de tomar el efecto por la causa e imaginar fines trascendentes de la naturaleza: "el sol da calor; el fin del sol es proporcionarnos calor a nosotros; tal orden natural debe ser intencionado por algo o alguien que lo quiso y nos conoce: ese es Dios". Y como nuestro conocer es imperfecto, suponemos que el ente que nos produjo tiene un conocimiento y una voluntad omnipotente y perfecta: antropologizamos la causa y afirmamos que Dios Creador Conoce y Quiere. Esta es una lucha que Spinoza sostiene contra la tradición escolástica y, en cierto sentido, contra toda filosofía que genera principios trascendentes.

Podríamos decir que existe un "principio de inmanencia" en Spinoza y que recorre la totalidad de su doctrina. La idea de inmanencia en Spinoza creemos tiene tres sentidos que a continuación señalamos:

a. Causa: expresa la forma de producción de la cosas. Las cosas se producen inmanentemente y eso tiene un significado negativo: no hay principios ad extra que sean el origen de lo producido. Pero positivamente, eso significa que existe una horizontalidad del Ser donde todos los elementos producidos tienen la misma dignidad ontológica y, por lo mismo, las jerarquías del tipo Creadorcreaturas, alma-cuerpo, razón-pasión se desvanecen.

8 “Así como hemos dicho, por parte de la causalidad, Dios es inmanente a las cosas que produce, mientras que por motivo de su esencia, las cosas debiendo estar todas en él, le son inmanentes. Pero, el hecho de que la causalidad inmanente consista en que ella produce sus efectos al interior de ella, la inmanencia de Dios hacia las cosas, implicada por la causalidad inmanente, abarca, ipso facto, la "inmanencia de las cosas en el mismo" (La traducción es nuestra). 
b. Ad intra: expresa una causa interior de producción. La inmanencia se refiere a una perfección interna de lo que se actualiza. Sin embargo, esta actualización interior no refiere a un agente o a un sujeto; la causa interna de producción abarca todo lo que pueda producirse, sin que llegue a confundirse ese "todo" con una categoría Universal.

c. Unidad del mundo: La inmanencia como principio refiere a la existencia de este mundo como el único real. No solo a nivel ontológico y epistemológico esas consecuencias se revelan, sino que "este mundo" se muestra como la fuente de todos los valores y la autoridad política. El entendimiento y la voluntad de Dios, la autoridad de la Escritura Sagrada, el poder divino devenido a los hombres: todos estos elementos se recusan por ser explicación trascendente de sucesos que tiene causa y explicación en un único mundo.

La Ética es la obra mayor de Spinoza, donde encontramos expresada la totalidad de su doctrina madura. Solo desde la Ética podemos hacer una lectura acabada y consecuente del sistema de Spinoza, sin reducir su doctrina a solo lo epistemológico, solo lo ontológico, solo lo político, solo lo social o solo lo afectivo. Desde el principio de inmanencia todos estos planos de investigación se atraviesan y se enriquecen, presentándonos una doctrina con un profundo potencial de análisis de la vida y el mundo.

\section{Conclusión}

Hemos hecho un recorrido que consta de tres momentos. El primero buscó posicionar a la Ética como la obra mayor de Spinoza y a la cual necesariamente se debe recurrir para dar una interpretación adecuada de su doctrina. Esto porque desde un aspecto comparativo con sus otras obras, tiene la forma adecuada -exposición geométrica- $\mathrm{y}$ esperada por Spinoza para exponer su propio pensamiento y, además, abarca en un sentido general todas las temáticas sobre las cuales Spinoza centra su pensamiento. Sin embargo, a la luz de lo expuesto, debemos dar cuenta de que la Ética tiene igualmente importancia, porque es la obra donde está contenida de manera más concisa, pero a la vez más potente la idea de causa inmanente. El "principio de inmanencia" puede explicar, por ejemplo, el motivo por el cual Spinoza radicaliza su realismo político en el TP. Se trata de analizar a los hombres tal como son, con su naturaleza afectiva incluida. No se trata de inventar quimeras conceptuales como un "contrato" político o decidir si existe una "buena" o "mala" naturaleza; se trata de analizar la política de los hombres tal como se da, incluidos sus apetitos y sus acciones.

El segundo momento buscó señalar la importancia de la causa inmanente al interior de la doctrina de Spinoza y para ello valoramos la posición que la prop. XVIII, "Dios es causa inmanente, pero no transitiva de todas las cosas", tiene al interior de la Ética. Nuestro análisis nos señala que es un momento fundamental. La Naturaleza Naturante y Naturaleza Naturada encuentran su "sentido productivo" al señalar de qué manera las cosas en el mundo se generan y cómo es la causa que los genera: es 
inmanente. Esto significa que esta substancia única que se identifica con Dios o la naturaleza total produce todo lo que se genera en el mundo de manera horizontal (las jerarquías dualista pierden sentido), ad intra (todo se genera desde el interior y nada se explica desde fuera) y en este mismo mundo (toda valoración y autoridad política de los hombres pertenece a este mundo y, por lo mismo, no existe criterio universal del bien y mal que juzgue la dignidad de un hecho moral o político).

En un último momento, hemos querido llegar a una definición de inmanencia spinozista y nos parece que los tres caracteres, causa, ad intra y unidad del mundo -de los cuales ya hemos hecho uso en el anterior párrafo como herramienta de análisis-, muestran toda la potencia del "principio de inmanencia". Desde Spinoza y la Ética, existe posibilidad de innumerables análisis, ya sea desde su vertiente ontológica, epistemológica, política o social-afectiva. Sin embargo, para ello debemos tomar la idea inmanencia como una lente que Spinoza pule con el mayor de los cuidados y desde la cual observa los fenómenos permanentemente. Sin ella, no podemos saber cómo las cosas se producen -corremos el riesgo de tergiversar su pensamiento- ni tampoco podemos vislumbrar todo el sentido práctico que tiene sus ideas. ¿Será esta omisión, pensamos, la causante de que no se ha recalcado suficientemente todo el valor que para Spinoza tiene pensar la vida? ¿Acaso Spinoza no afirma solemnemente en la Ética: "un hombre libre en nada piensa menos que en la muerte, y su sabiduría no es una meditación de la muerte, sino de la vida"? (2011: IV, prop. LXVII, 389). Es por lo mismo que nada hay mejor que la palabra de Spinoza y de la Ética para concluir este escrito y para mostrarnos cómo la vida y la práctica (que son una y la misma) cobran sentido si pensamos desde la perspectiva de la inmanencia:

"Queda solo por indicar cuán útil es para la vida el conocimiento de esta doctrina, lo que advertiremos fácilmente por lo que sigue, a saber:

$1^{\circ}$ En cuanto nos enseña que obramos por el solo mandato de Dios, y somos partícipes de la naturaleza divina, y ello tanto más cuanto más perfectas acciones llevamos a cabo, y cuanto más y más entendemos a Dios. Por consiguiente, esta doctrina, además de conferir al ánimo un completo sosiego, tiene también la ventaja de que nos enseña en qué consiste nuestra más alta felicidad o beatitud, a saber: en el solo conocimiento de Dios, por el cual somos inducidos a hacer tan solo aquello que el amor y el sentido del deber aconsejan. Por ello entendemos claramente cuánto se alejan de una verdadera estimación de la virtud aquellos que esperan de Dios una gran recompensa en pago a su virtud y sus buenas acciones, como si se tratase de recompensar una estrecha servidumbre, siendo así que la virtud y el servicio de Dios son ellos mismos la felicidad y la suprema libertad. $2^{\circ}$ En cuanto enseña cómo debemos comportarnos ante los sucesos de la fortuna (los que no caen bajo nuestra potestad, o sea, no se siguen de nuestra naturaleza), a saber: contemplando y soportando con ánimo equilibrado las dos caras de la suerte, ya que de los eternos decretos de Dios se siguen todas las cosas con la misma necesidad con que se sigue de la esencia del triángulo que sus tres ángulos valen dos rectos.

$3^{\circ}$ Esta doctrina es útil para la vida social, en cuanto enseña a no odiar ni despreciar a nadie, a no burlarse de nadie ni encolerizarse contra nadie, a no envidiar a nadie. Además es útil en cuanto enseña a cada uno a contentarse con lo suyo, y a auxiliar 
al prójimo, no por mujeril misericordia, ni por parcialidad o superstición, sino solo por la guía de la razón, según lo demanden el tiempo y las circunstancias, como mostraré en la Cuarta Parte.

$4^{\circ}$ Por último, esta doctrina es también de no poca utilidad para la sociedad civil, en cuanto enseña de qué modo han de ser gobernados y dirigidos los ciudadanos, a saber: no para que sean siervos, sino para que hagan libremente lo mejor" (2011: II, prop. XLIX, schol., 202-203).

\section{Referencias bibliográficas}

Balibar, Étienne (2011), Spinoza y la Política. Buenos Aires: Prometeo Libros. Deleuze, Gilles (2008), En Medio de Spinoza. Buenos Aires: Editorial Cactus. Giancotti, Emilia (1970), Lexicon Spinozanium, 2 vol. La Haye: Martinus Nijhoff. Gueroult, Martial (1968), Spinoza, Dieu (Ethique, 1). París: Editions Montaigne. Nadler, Steven (2004), Spinoza. Madrid: Editorial Acento.

Spinoza, Baruch (1988), Correspondencia Completa. Traducción de Domingo Sánchez. Madrid: Ediciones Hiperión.

(2000), Ética. Traducción de Atilano Domínguez. Madrid: Editorial Trotta.

(2011), Ética. Traducción de Vidal Peña. Madrid: Alianza Editorial.

(1972), Opera Spinoza. Carl Winters Universitaetsbuchhandlung, Heidelberg.

(1990), Tratado Breve. Traducción de Atilano Domínguez. Madrid: Editorial Alianza.

(2006), Tratado de la Reforma del Pensamiento; Principios de la filosofía de Descartes; Pensamientos Metafísicos. Traducción de Atilano Domínguez. Madrid: Editorial Alianza.

(2010), Ethica DB. Publicación numérica y multilingüe de la Ética de Spinoza. http://ethicadb.org/plan.php?lanid=0\&lg=es. Consulta: 1 de abril de 2014. 